\title{
3 Research Square \\ Can thickness of subcutaneous fat tissue limit emergency percutaneous cricothyrotomy?
}

\section{Tomasz Sanak}

Center for Innovative Medical Education, Jagiellonian University Medical College, Cracow

\section{Ositadima Chukwu}

Student's Scientific Group at the Chair of Radiology, Jagiellonian University Medical College, Cracow

\section{Anna Gabryś}

Student's Scientific Group at the Chair of Radiology, Jagiellonian University Medical College, Cracow

\section{Jakub Giliavas}

The University Hospital in Cracow

Katarzyna Ciuk ( $\sim$ c.katarzyna.anna@gmail.com )

Student's Scientific Group at the Chair of Radiology, Jagiellonian University Medical College, Cracow

Marta Kalek

Student's Scientific Group at the Chair of Radiology, Jagiellonian University Medical College, Cracow Andrzej Urbanik

Department and Chair of Radiology, Jagiellonian University Medical College, Cracow

\section{Research Article}

Keywords: cricothyrotomy, difficult neck anatomy, emergency airway management, needle cricothyrotomy, obesity

Posted Date: November 5th, 2021

DOI: https://doi.org/10.21203/rs.3.rs-1032432/v1

License: (c) (i) This work is licensed under a Creative Commons Attribution 4.0 International License. Read Full License 


\section{Abstract \\ Background}

Needle cricothyrotomy is a method of maintaining airways in emergency situations. One of identified factors that can make this procedure difficult to perform is 'difficult neck anatomy' or short obese neck. Due to the growing problem of obesity, we decided to estimate feasibility of needle cricothyrotomy by measuring the thickness of neck fat tissue in the population. Evaluation of this method is important because it is the only method that can be legally performed by paramedics in Poland. The aim of the study was to estimate feasibility of needle cricoidectomy by evaluating the percentage of population in which the thickness of subcutaneous fat tissue could potentially limit or complicate such a procedure.

\section{Methods}

In this retrospective study we reviewed CT scans of the neck from a database at the Department of Radiology, University Hospital in Cracow. 550 CT scans met inclusion criteria: age of patient over 18 years old, lack of any lesions altering anatomy of measured region of neck, the first CT scan of patient. 50.36\% of patients were women. Median age was 61 years (range 18 -93). The distance from the skin surface at the level of the lower edge of the thyroid cartilage to the cricothyroid ligament (surface - ligament distance, SLD) was measured. Statistical analysis of the data was performed using R software (R version 4.0.3).

\section{Results}

Median SLD was 1.41 (1.01 - 2.04). Subcutaneous fat tissue was thicker than maximal depth of application of cricothyrotomy $(3 \mathrm{~cm})$ device in 31 patients $(5.64 \%)$.

\section{Conclusions}

Performing needle cricothyrotomy may be limited in a considerable percentage of population (5.64\%).

\section{Introduction}

Percutaneous cricothyroidotomy is an emergency procedure that is used in a life-threatening airway obstruction to obtain ventilation and oxygenation when other, non-invasive techniques are ineffective or contraindicated. This situation is also known as a 'cannot intubate, cannot oxygenate' situation (Cl-CO). Cricothyroidotomy may be performed by puncture (needle cricothyroidotomy) or surgical incision (surgical cricothyroidotomy) of the cricothyroid membrane [1]. 
Needle cricothyroidotomy is performed by puncturing the cricothyroid membrane by the needle and passing a catheter through it. This procedure provides temporary access to the airways. Surgical cricothyroidotomy requires a horizontal incision through the lower part of the cricothyroid membrane and passing a tracheostomy or endotracheal tube into the trachea. Surgical cricothyroidotomy provides more effective ventilation than needle cricothyroidotomy because of the larger diameter of the used tube [2].

It is important to distinguish these different techniques of emergency airway access because paramedics in the Emergency Medical Services in Poland are capable of performing only the needle cricothyroidotomy procedure. It is set out by the Regulation of the Minister of Health from 16 December 2019 [3].

Nowadays, the issue of obesity is very common. It can cause several obstacles during medical procedures including getting access to the obstructed airways [4]. Cricothyroidotomy as a technically difficult procedure is especially problematic in patients with thick layer of neck fat tissue or short neck. Additionally, the kits for cricothyroidotomy and the user manual do not include the limit values of the distance from the skin surface to the airways at which the procedure is possible to perform.

Aim

The aim of the study was to estimate feasibility of needle cricoidectomy by evaluating percentage of population in which the thickness of subcutaneous fat tissue could potentially limit or complicate such a procedure.

\section{Materials And Methods}

We retrospectively reviewed radiological images from a database at the Department of Radiology, University Hospital in Cracow. We searched for computed tomography (CT) scans of the neck in a sagittal plane. We collected a database of CT scans of 600 patients from the period between 2015-2019.

The study protocol complied with the Declaration of Helsinki and was approved by the Bioethics Committee of Jagiellonian University in Cracow, Poland (No 1072.6120.194.2021.). The need of informed consent from all subjects was waived due to the nature of the study.

The inclusion criteria comprised patients aged over 18 years old that underwent CT scan of the neck. Only the first CT scan of a certain patient was used in case the patient had more than one CT scan during a given period of time. The exclusion criteria were as follows: age below 18 years old, second and further CT scans of the same patient, any lesions that altered anatomy of the measured region of neck such as tumors, hematomas, abscesses, enlarged lymph nodes or thyroid glands. We excluded 50 patients, causes of exclusion were enlarged thyroid glands (15 pts), abscesses or inflammatory changes (2 pts), neoplasm of larynx (10pts), enlarged lymph nodes or hematological neoplasm located in soft tissue of neck (15pts), hematoma located in soft tissues of neck (1pt), tracheostomy (7pts). 
We investigated CT scans of 550 patients, 277 (50.36\%) of them were women. Median age was 61 (44 69) years with range $18-93$.

Two measurements were made. The first measurement was the distance from the skin surface measured at the level of the lower edge of the thyroid cartilage to the cricothyroid ligament (surface - ligament distance SLD). The second measurement was the diameter of the respiratory tract (DR) measured from the cricothyroid ligament to the posterior wall of the subglottic region of the larynx (Figure 1). We also collected data such as age and gender of the patient.

We manually measured the maximal length of the application of the device (cannula and metal needle) by measuring the length of the applicable part of the device after removing the stopper. The maximum depth of application was $3 \mathrm{~cm}$.

Based on the maximal length of application and performed measures we calculated the ratio between the difference of maximal length of application and SLD divided by DR (length of device in airways to the diameter of respiratory tract ratio DDR). This measure tells us how deep the device could be placed in the airways (Figure in the supplementary material).

Emergency percutaneous cricothyroidotomy equipment

There are two types of cricothyrotomy kits available on the market. Two sizes of sets are available depending on the patient's weight. One for pediatric patients $(10-35 \mathrm{~kg})$ and one for adults and older children $(>35 \mathrm{~kg}$ ). The kit for adults consists of one syringe (with a cricothyrotomy needle, conical cannula and safety stopper), one connecting tube with adapter and one cushion neckband (Figure 2).

There are also kits for a classical surgical technique of cricothyrotomy. They contain a scalpel, a syringe, a cuffed tracheal tube with a dilator, a neck tape, an extension tubing, a tracheal hook, blunt scissors, a speculum.

The measured maximum depth of application of the tracheal tube size 7 was $4.5 \mathrm{~cm}$.

\section{Statistical analysis}

Statistical analysis of the data was performed using R software (R version 4.0.3). Quantitive measurements were expressed as a median (IQR), and inner group comparisons were performed using Mann-Whitney $U$ test. Qualitative data were expressed as percentages, Fisher exact probability test was used for the data comparisons between groups. $95 \% \mathrm{Cl}$ intervals were computed using the exact method.

Differences were considered statistically significant when $P \leq 0.05$. All reported $P$ values were two sided and were not adjusted for multiple testing.

\section{Results}




\section{SLD}

Median SLD was 1.41 (1.01 - 2.04). Distribution of SLD is shown in Figure 3. In 31 patients $(5.64 \%, 95 \mathrm{Cl}$ $3.86 \%-7.91 \%)$ SLD exceeded $3 \mathrm{~cm}$. In 13 patients (2.36\%, 95CI 1.26\% - 4.01\%) SLD exceeded 3.5cm. In 1 patient $(0.19 \% 95 \mathrm{Cl} 0 \%-1.01 \%)$ SLD exceeded $4.5 \mathrm{~cm}$. SLD was not significantly correlated with age and gender (Table 1).

Table 1

Correlations between SLD and ADR and age and gender. Mann-Whitney $U$ test was used for comparisons between genders, parameters are shown as median (IQR). Pearson correlation coefficient was used to measure correlation between age and measures, absolute values less than 0.2 were treated as lack of correlation.

\begin{tabular}{|c|c|c|c|c|c|}
\hline & Gender & & & Age & \\
\hline & Male & Female & $\mathrm{P}$ & $\begin{array}{l}\text { Pearson Correlation } \\
\text { coefficient }\end{array}$ & $P$ \\
\hline $\begin{array}{l}\text { SLD } \\
{[\mathrm{cm}]}\end{array}$ & $\begin{array}{l}1.39(0.94- \\
2.1)\end{array}$ & $\begin{array}{l}1.43(1.05- \\
2.02)\end{array}$ & 0.2961 & 0.19 & $<0.001$ \\
\hline $\begin{array}{l}\text { ADR } \\
{[\mathrm{cm}]}\end{array}$ & $\begin{array}{l}2.25(2.03- \\
2.49)\end{array}$ & $1.82(1.64-2.08)$ & $<0.001$ & 0.08 & 0.0622 \\
\hline
\end{tabular}

Mean SLD was $1.58 \pm 0.79$.

DR

Median DR was 2.04 (1.75 - 2.34). Men had significantly larger DR $(P<0.001)$. DR was not correlated with age (Table 1). Mean DR was $2.1 \pm 0.5$.

\section{DDR}

DDR was less than $50 \%$ in 158 patients $(28.73 \% 95 \mathrm{Cl} 24.98 \%-32.71 \%)$. DDR was less than $25 \%$ in 83 patients $(15.09 \% 95 \mathrm{Cl} 12.20 \%$ - 18.36\%). DDR was less than $10 \%$ in 45 patients $(8.18 \% \mathrm{Cl} 6.03 \%$ $10.79 \%)$.

\section{Discussion}

Obesity is being more and more common, in 2015107.7 million children and 603.7 million adults in 70 countries were obese [5]. Every overweight person and especially obese people are a challenge for medical equipment and personnel [6].

Lifesaving procedures need to be constantly improved and validated. The aim of our study was to estimate feasibility of needle cricothyrotomy. We measured the percentile of patients with a thickness of layer of adipose tissue on the neck that could potentially be an obstacle in performing such a procedure. 
Obesity is associated with a thicker layer of adipose tissue. Cricothyrotomy device may be too short and palpation of crucial anatomical structures may be implausible. However, every patient has an equal right to medical services based on the current state of medical science [7]. Medical workers and the medical industry are obliged to prepare adequate procedures and equipment for patients with different body sizes.

Our study shows that a considerable percentage of the population $(5.64 \%)$ has a thick $(>3 \mathrm{~cm})$ layer of neck fat tissue. The maximal length of application of device used for needle cricoidectomy is $3 \mathrm{~cm}$, thus performing needle cricothyrotomy is potentially limited or more difficult in that part of population. In addition, in $8.18 \%$ needle cricoidectomy device would be relatively superficially placed (DDR $<10 \%$ ) in the respiratory tract. We measured maximal depth of application of the device after removing the stopper, thus this depth is larger than usual depth of inserting Qiuicktrach during puncturing the cricothyroid membrane. Gender and age were not associated with larger SLD.

After thorough search through the PubMed database we did not find any other study evaluating distribution of thickness of neck fat tissue in patients' populations.

Hossfeld et. al. carried out a study, in which on four anatomical neck variations (long slim/long obese/short slim/short obese) two surgical approaches to cricothyroidotomy were performed. The results showed that the time to access airways was longer in the short obese group than in the long slim group and the risk of unsuccessful procedures was increased in the short obese group compared to the long slim group. This study showed that difficulties in cricothyroidotomy may arise from the anatomical factors such as the thickness of the skin of the patient's neck. [4]

Some previous studies showed that standard medical procedures may be inadequate for severely obese patients $[8,9,10]$. Obese people may need different equipment for needle decompression of a tension pneumothorax, due to larger chest wall thickness. At the time of that study (2013) the largest available needle $(64 \mathrm{~mm})$ for such a procedure was suitable for $79 \%$ of the patients. Positive correlation between $\mathrm{BMI}$ and chest wall thickness was proven. Previous study showed that a catheter of length of $4.5 \mathrm{~cm}$ may be too short for a substantial amount (9.9-35.4\%) of the population, depending on age and gender. The review of literature showed that $8 \mathrm{~cm}$ needle would be suitable for $96-99 \%$ percent of patients [9]. Thus, we see a similar situation where equipment and procedures had to be adjusted in case of obesity.

Considerable $(>5 \%)$ and potentially growing percentage of population in which needle cricothyrotomy is limited raises question what are treatment options for them. For the reason explained below we believe that surgical cricothyrotomy would be adequate.

When similar problems arose with performing needle decompression of a tension pneumothorax enlarging size of the needle were sufficient resolution. In case of needle cricothyroidotomy this might not be the case. Larger size of needle is associated with a higher rate of complications [11] and size of needle might not be the only problem in performing this procedure in obese patients, another one might be palpating the landmarks. 
The first step of performing cricothyrotomy is locating the cricothyroid membrane. Anatomical landmarks such as thyroid prominence and the gap between lower thyroid cartilage and the cricoid ring can be usually located by palpation - performing "laryngeal handshake". Thick fat layer can make this spots undetectable and performing cricothyrotomy would be more difficult.

Performing surgical cricothyrotomy is preferred over elective tracheostomy in obese patients due to difficult neck anatomy [12]. Open surgical access provides visibility of crucial anatomical structures [13]. Without that, locating the precise place of insertion of cannula is often impossible due to large thickness of fat tissue or "lack of neck" [12].

Given the fact that half of performed needle cricothyroidotomy procedures are unsuccessful, search for additional methods is justified even if they would potentially make the procedure longer. Performing USG to measure the distance from skin to airways before making cricothyrotomy in patients with difficult neck anatomy is also a potential field of investigation.

Based on literature and clinical experience, we recommend using surgical cricothyrotomy rather than needle cricothyrotomy in patients with thick layer of neck fat tissue, and we suggest expanding the range of legal therapeutic possibilities for prehospital personnel. Surgical method of cricothyrotomy was shown to be easier to learn for Surgical airway-naive medical personnel than needle cricothyrotomy [14].

Study limitations

Actual percentage of people with high SLD in the overall population can be lower due to possible selection of study population.

Measurements used in our study are entirely theoretical and are based on the assumption that a layer of fat tissue of thickness larger than the maximal depth of application of an emergency cricothyrotomy device can possibly limit performance of emergency cricothyrotomy. Those measures do not take into biomechanical properties of fat tissue into account.

There is also a possibility that distances measured in CT are larger because of the position of the head. The head bent back may cause flattening of the subcutaneous layer of the neck. However, bending neck is not recommended in patients with neck trauma, thus our study may be more accurate for this type of situation.

\section{Conclusions}

Our study supports the thesis that needle cricothyrotomy is limited in a significant percentage of population (5.64\%).

Need for further studies 
There is a need for several other studies: study correlating neck fat tissue with BMl; study measuring SLD on population of emergency patients who needed cricothyrotomy to assess feasibility and rate of complication in patients with thick layer of neck fat tissue; functional study of changes of thickness of fat tissue on the neck depending on the position of head and study correlating thickness of fat tissue with accessibility of anatomical landmarks.

\section{Abbreviations}

$\mathrm{Cl}-\mathrm{CO}$, cannot intubate, cannot oxygenate' situation; $\mathrm{CT}$, computed tomography; DDR, length of device in airways to the diameter of respiratory tract ratio; DR, diameter of the respiratory tract; SLD, surface ligament distance

\section{Declarations}

\section{Ethics approval and consent to participate}

The study protocol complied with the Declaration of Helsinki and was approved by the Bioethics Committee of Jagiellonian University in Cracow, Poland (No 1072.6120.194.2021.). The need of informed consent from all subjects was waived due to the nature of the study.

\section{Consent for publication}

Not applicable

\section{Availability of data and materials}

Not applicable

\section{Competing interests}

The authors declare that they have no competing interests.

\section{Funding}

Not applicable

\section{Authors' contributions}

TS designed the study. AG, JG and MK collected the data. OC performed statistical analysis of the data. $\mathrm{OC}, \mathrm{TS}, \mathrm{KC}$ and $\mathrm{AU}$ wrote the manuscript. All authors read and approved the final manuscript.

\section{Acknowledgements}

Not applicable 


\section{References}

1. Hamaekers $\mathrm{AE}$, Henderson JJ. Equipment and strategies for emergency tracheal access in the adult patient. Anaesthesia. 2011 Dec;66 Suppl 2:65-80. doi: 10.1111/j.1365-2044.2011.06936.x. PMID: 22074081.

2. Needle cricothyroidotomy with percutaneous transtracheal ventilatio, Manoj K Mittal, MD, https://www.uptodate.com/contents/needle-cricothyroidotomy-with-percutaneous-transtrachealventilation

3. Regulation of the Minister of Health from 16 December 2019 on medical rescue activities and health services other than medical rescue activities that may be provided by a paramedic; Rozporządzenie Ministra Zdrowia z dnia 16 grudnia 2019 r. w sprawie medycznych czynności ratunkowych i świadczeń zdrowotnych innych niż medyczne czynności ratunkowe, które mogą być udzielane przez ratownika medycznego (Dz. U. z 2019 r., poz. 2478)

4. Hossfeld B, Mahler O, Mayer B, Kulla M, Helm MNecessity to depict difficult neck anatomy for training of cricothyroidotomy. European Journal of Anaesthesiology. 2019;36(7):516-523. doi: 10.1097/EJA.0000000000000993.

5. GBD 2015 Obesity Collaborators. (2017). Health effects of overweight and obesity in 195 countries over 25 years. New England Journal of Medicine, 377(1), 13-27. DOI: 10.1056/NEJMoa1614362

6. Bein, B., Höcker, J., Fudickar, A., \& Scholz, J. (2009). Anaesthesia management of the obese patient. Anasthesiologie, Intensivmedizin, Notfallmedizin, Schmerztherapie: AINS, 44(9), 600. DOI: $10.1055 / \mathrm{s}-0029-1241164$

7. Wolff, J. (2012). The Human Right to Health (Norton Global Ethics Series). WW Norton \& Company

8. Zengerink, I., Brink, P. R., Laupland, K. B., Raber, E. L., Zygun, D., \& Kortbeek, J. B. (2008). Needle thoracostomy in the treatment of a tension pneumothorax in trauma patients: what size needle?. Journal of Trauma and Acute Care Surgery, 64(1), 111-114. DOI: 10.1097/01.ta.0000239241.59283.03

9. Carter TE, Mortensen CD, Kaistha S, Conrad C, Dogbey G. Needle decompression in appalachia do obese patients need longer needles?. West J Emerg Med. 2013;14(6):650-652. doi:10.5811/westjem.2013.7.15844

10. Laan DV, Vu TD, Thiels CA, et al. Chest wall thickness and decompression failure: A systematic review and meta-analysis comparing anatomic locations in needle thoracostomy. Injury. 2016;47(4):797804. doi:10.1016/j.injury.2015.11.045

11. Katayama A, Watanabe $\mathrm{K}$, Tokumine $\mathrm{J}$, et al. Cricothyroidotomy needle length is associated with posterior tracheal wall injury: A randomized crossover simulation study (CONSORT). Medicine (Baltimore). 2020;99(9):e19331. doi:10.1097/MD.0000000000019331 
12. Rehm, C.G., Wanek, S.M., Gagnon, E.B. et al. Cricothyroidotomy for elective airway management in critically ill trauma patients with technically challenging neck anatomy. Crit Care 6, 531 (2002). https://doi.org/10.1186/cc1827

13. Frerk, C., Mitchell, V. S., McNarry, et all (2015). Difficult Airway Society 2015 guidelines for management of unanticipated difficult intubation in adults. BJA: British Journal of Anaesthesia, 115(6), 827-848. DOI: 10.1093/bja/aev371 alt

14. Heymans F, Feigl G, Graber S, Courvoisier DS, Weber KM, Dulguerov P. Emergency Cricothyrotomy Performed by Surgical Airway-naive Medical Personnel: A Randomized Crossover Study in Cadavers Comparing Three Commonly Used Techniques. Anesthesiology. 2016 Aug;125(2):295-303. doi: 10.1097/ALN.0000000000001196

\section{Figures}

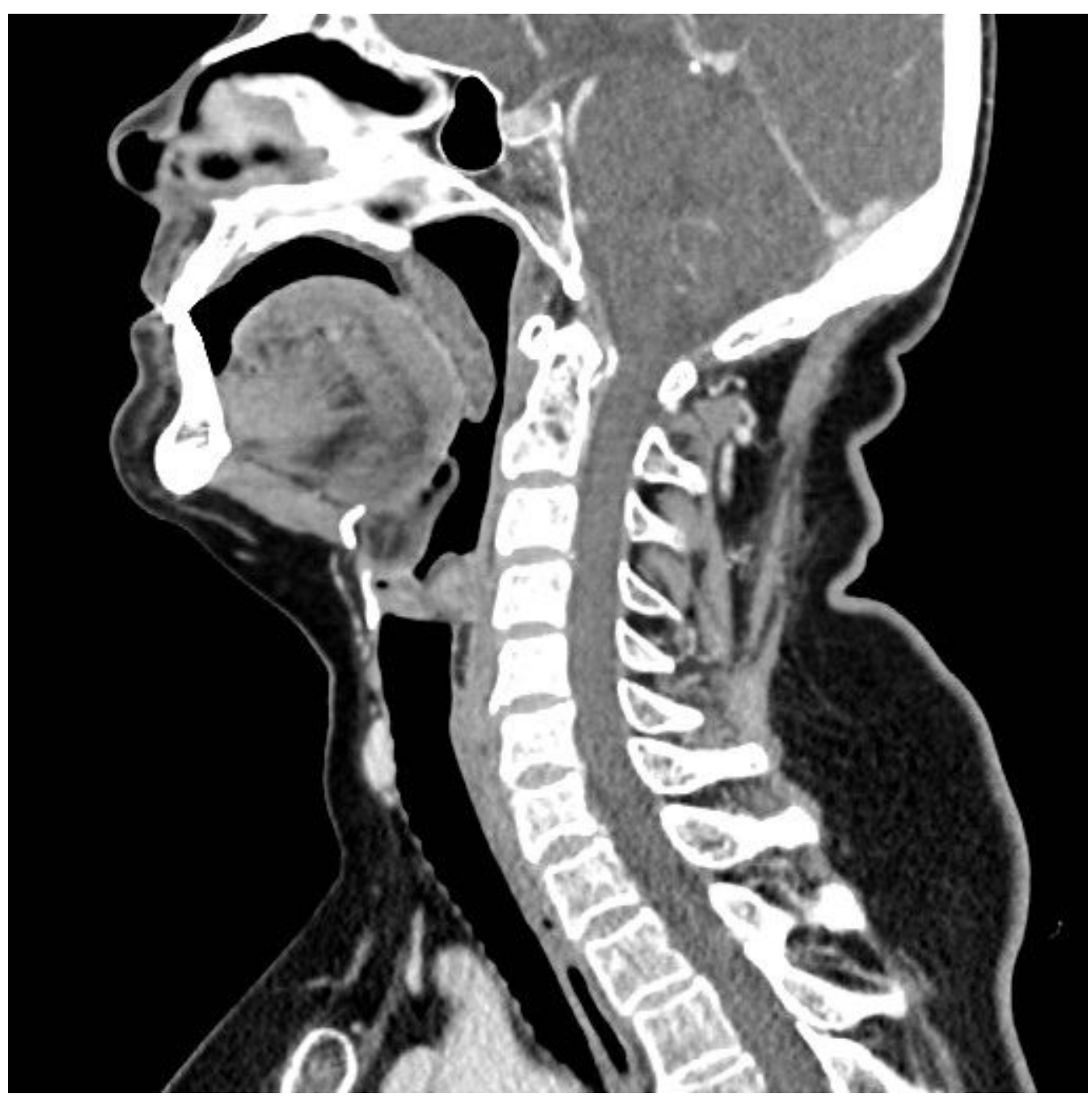

\section{Figure 1}

CT scan of neck used to assess SLD and DR 


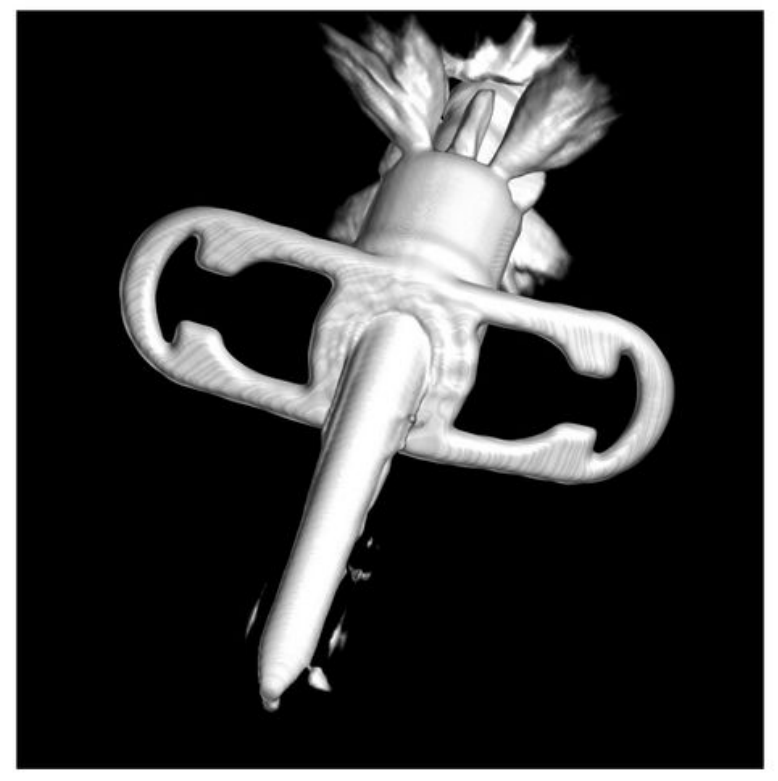

A) view from above.

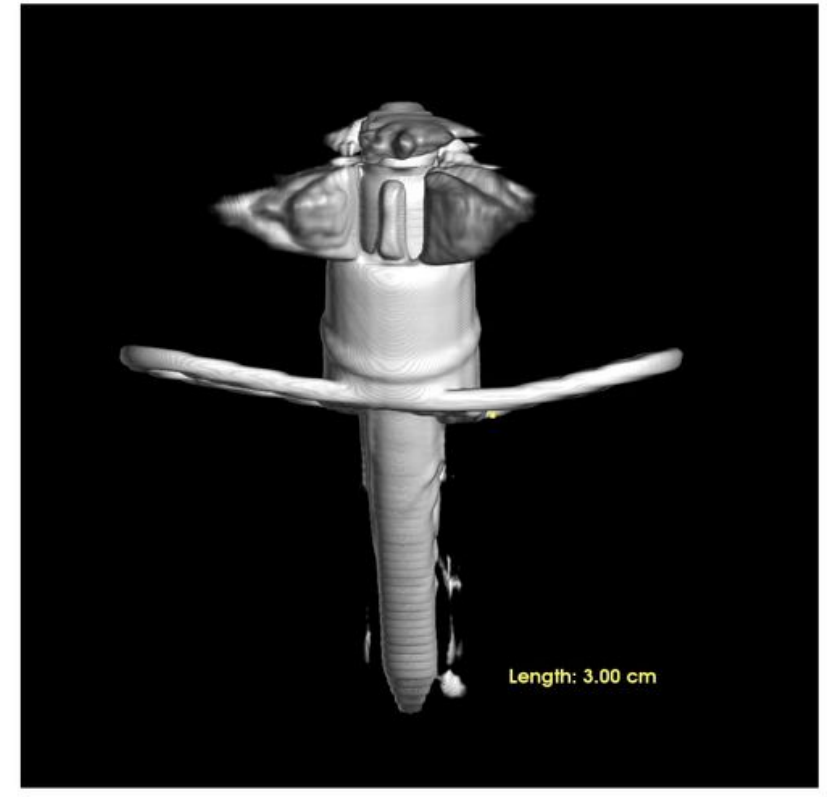

B) vertical view with maximal depth of application.

Figure 2

$3 \mathrm{D}$ visualizations of cricothyrotomy device based on CT scans. 


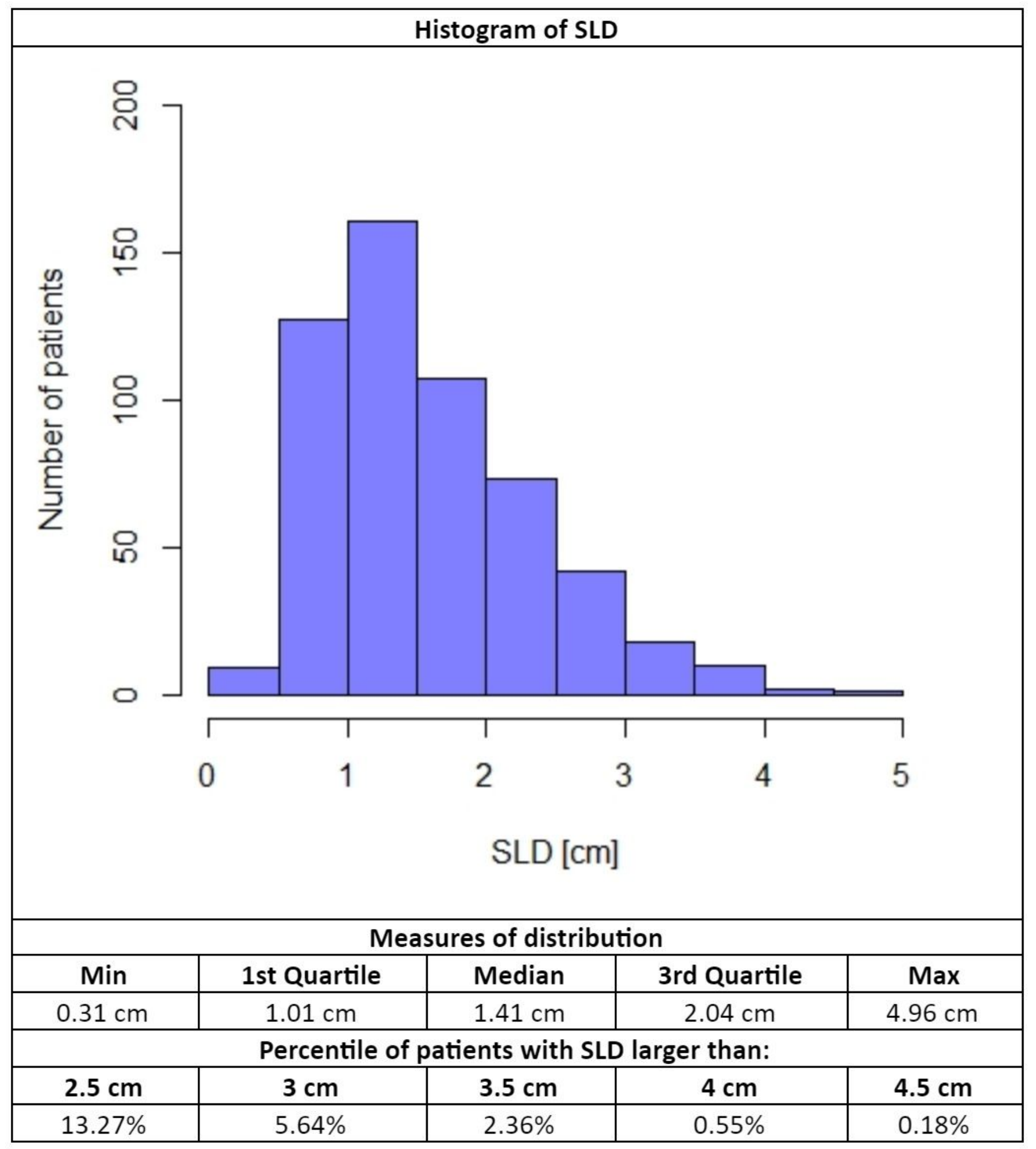

Figure 3

Histogram of SLD.

\section{Supplementary Files}

This is a list of supplementary files associated with this preprint. Click to download. 
- supplementarymaterial2.11.21.pdf 